\title{
Oral contraceptive phase has no effect on endurance test
}

C. Rechichi ${ }^{1}$, B. Dawson ${ }^{2}$, C. Goodman ${ }^{2}$

${ }^{1}$ ACS, WA Institute of Sport, Perth, Australia

${ }^{2}$ Department of Human Movement and Exercise Science, University of Western Australian, Perth, Australia

\section{ABSTRACT}

Thirteen female cyclists/triathletes (mean peak $\mathrm{VO}_{2}=53.0 \pm 5.6 \mathrm{ml} \mathrm{kg}^{-1} \cdot \mathrm{min}^{-1}$ ) using a monophasic OC, performed an endurance test (1-h cycle) at three time points of an $\mathrm{OC}$ cycle. Testing times were during the $\mathrm{OC}$ consumption phase (CONS), early in the OC withdrawal phase (WITH1) and late in the OC withdrawal phase (WITH2). Resting endogenous serum estradiol and progesterone concentrations were measured. Power output, heart rate, $V_{E}$, $\mathrm{VO}_{2}, \mathrm{RER}, \mathrm{RPE}$, blood lactate and blood glucose were measured throughout the 1-h test. Serum oestradiol levels were greater during WITH2 compared to the CONS $(p<0.05)$, however there was no difference in serum progesterone levels. No significant differences were present between the testing times ( $p>0.05)$ for mean power output $(172-173 \mathrm{~W})$, heart rate (163-166 bpm), $\mathrm{VO}_{2}$ (41.3-41.7 mL kg-1. $\left.\mathrm{min}^{-1}\right)$, RER (0.93-0.94), RPE (14.5-14.8) and blood glucose concentration (5.3-5.5 mmol $\mathrm{L}^{-1}$ ). Greater mean $\mathrm{V}_{\mathrm{E}}$ (by 3.4 and 5.7 $\mathrm{L} \cdot \mathrm{min}^{-1}$ ) and $\mathrm{V}_{\mathrm{E}} / \mathrm{VO}_{2}$ (by 1.0 and 2.0 ) values were measured during CONS compared to WITH1 and WITH2 respectively and blood lactate values (by 1.2 $\left.\mathrm{mmol} \mathrm{L}^{-1}\right)$ compared to WITH1 only $(p<0.05)$. Despite variation in some physiological variables, there was no difference in endurance performance throughout an OC cycle in endurance trained female athletes.

Keywords menstrual cycle, cycling, ventilation, lactate, oxygen consumption. 


\section{INTRODUCTION}

A number of physiological variables are reported to vary with fluctuations in female reproductive hormones seen throughout a menstrual cycle (18). However many findings remain largely inconclusive, probably due to the high intra- and inter- individual variability in estrogen and progesterone concentration, in conjunction with the pulsatile nature of the secretion of these hormones (17). For this reason, the oral contraceptive (OC) cycle may provide a more stable environment to evaluate the acute effect of reproductive hormones on physiological variables and exercise performance in women.

Despite the widespread use of OC agents by female athletes (8), OC users have not been included in the majority of menstrual cycle research and limited information exists regarding the influence of OC usage on the exercise responses of women. The majority of the literature has looked at sub-maximal aerobic exercise and has typically been performed on non-athletes $(3,9,15)$. Predominantly, the physiological differences between OC users and nonusers, or pre and post OC treatment have been researched $(1,5,11,19,21,25)$, with little data pertaining to variations within an OC cycle.

Of the studies that have investigated aerobic exercise parameters within an OC cycle most have found no variation as a result of acute hormonal change $(7,15,20)$. However, these findings may be limited because tests were conducted at times when the synthetic hormone intake would have been similar, as opposed to testing during the clearance times either pre-menstrual or menstrual, when there is a greater contrast in hormone levels. Further 
limitations of the existing $O C$ research include small subject numbers, large variation in the timing of test days and the types of $\mathrm{OC}$ used.

In some studies the use of an OC has been associated with decreases in $\mathrm{VO}_{2}$ max, ranging from 5 to $15 \%$, following two to four months of OC use in both untrained subjects and trained athletes $(10,19,25)$. In addition, substrate metabolism has been found to vary with $\mathrm{OC}$ use. Most studies suggest that there is a slight reduction in carbohydrate metabolism during sub-maximal aerobic exercise with OC use, primarily due to a decreased dependence on glycogen and altered secretion rates of gluco-regulatory hormones $(1,3,5$, $, 12,21)$. Some studies have also reported increases in fat metabolism during exercise with OC use $(5,9,16,23)$, whilst others demonstrated no difference $(1,25)$. It is possible that the variation in test protocols, including exercise mode, duration and intensity has influenced these findings, as well as the use of different OC agents. For example, in one of the earlier studies (5) subjects used OC formulations that contained 50ug of estrogen, unlike the modern day combinations that contain 20-30ug of estrogen. Recent research (12) has demonstrated that estrogen and progesterone have opposing actions on substrate metabolism. The findings suggest that the ratio of these hormones (endogenous and/or exogenous) may be important in determining the impact of menstrual cycle or OC phase on athletic performance.

The purpose of this study was to examine whether endurance performance is affected by acute hormonal fluctuation within an OC cycle, in trained female athletes taking monophasic OC agents. The data should assist female 
athletes in making more informed decisions about the role of $\mathrm{OC}$ agents in manipulating the menstrual cycle, with a view to optimizing performance. It should also determine whether it is necessary to consider OC cycle phase for routine and research based scientific testing. We hypothesized that endurance performance would be optimal during the consumption phase of the OC cycle, as a result of a shift in substrate metabolism toward increased fat metabolism, and reduction in glycogen depletion and blood lactate accumulation.

\section{METHODS}

Thirteen trained $\left(\right.$ mean \pm SD peak $\mathrm{VO}_{2}=53.0 \pm 5.6 \mathrm{ml}^{\mathrm{kg}}{ }^{-1} \cdot \mathrm{min}^{-1}$, range $47.5-$ $58.2 \mathrm{ml} \mathrm{kg}^{-1} \cdot \mathrm{min}^{-1}$ ) female cyclists or triathletes taking a monophasic OC participated in the study. Their characteristics are presented in Table 1.All participants were informed of the purpose of the study, the risks and responsibilities of participation and were required to give their written consent. The Human Research Ethics Committee of the University of Western Australia approved the research.

Insert Table 1

\section{Experimental Overview}

Each participant attended a familiarization session, followed by an incremental test to determine both peak $\mathrm{VO}_{2}$ and lactate threshold (this test was randomized for OC cycle phase). Approximately 4-7 days later, the first of three endurance performance tests were completed. A common monophasic 
OC consists of 21 active pills containing a constant concentration of estradiol and progestogen, and seven inactive/sugar pills. The three test days were selected to represent the varied hormonal profiles seen within a normal monophasic OC cycle, as outlined below:

CONS - between days 13 and 17 of active OC consumption WITH1 - early in the withdrawal phase, 2-3 days post active pill cessation WITH2 - late in the withdrawal phase, 6-7 days post active pill cessation

Test order was balanced with respect to OC cycle phase and test time was standardized between 6:00 and 7:00am for each participant (with the exception of one participant who performed all tests at 6:00pm). Over the testing period participants were asked to maintain a regular and constant volume/intensity of training. They were also asked to standardize their dietary intake in the 24 hours prior to each test. Body mass and skinfold thickness at seven different sites were assessed prior to all tests, which were performed on a calibrated wind-braked cycle ergometer (Evolution, Evolution Performance Cycles, Victoria, Australia), interfaced to a computer with specifically designed software (Cycle Ergometer Data Acquisition and Analysis, Western Australian Institute of Sport), in controlled environmental conditions.

\section{Assessment of peak oxygen uptake}

The test commenced at an initial workload of $50 \mathrm{~W}$ and subsequent $25 \mathrm{~W}$ increments were applied every 3 minutes until volitional fatigue. The 
methodology for the test, the assessment of oxygen uptake and lactate analysis was as described by Bishop, 1997 (4).

\section{Assessment of Endurance Performance}

Following a standardized warm up, endurance performance was assessed by the calculated mean power output $(\mathrm{W})$ produced by the participant during a $1 \mathrm{~h}$ cycle test. The cyclists were instructed to produce the greatest power output possible throughout the test. For the initial eight minutes of exercise, power output was preset at the individual's lactate threshold (determined from the results of the incremental test) and thereafter the subject was free to alter pedal force, gears and cadence. They were provided with constant visual feedback of power output, pedal cadence, heart rate and elapsed time (4). Each participant was permitted to ingest water ad libitum during the test, at two intervals between 20-25 min and 40-45 min.

\section{Oxygen consumption}

Throughout the test participants were fitted with a breathing valve (which was removed to permit ingestion of fluids between $20-25 \mathrm{~min}$ and $40-45 \mathrm{~min}$ ) and expired air was analyzed for $\mathrm{O}_{2}$ and $\mathrm{CO}_{2}$ concentrations using Ametek gas analyzers (SOV S-3A and COV CD3A respectively, Pittsburgh, USA) and ventilation $\left(\mathrm{V}_{\mathrm{l}}\right)$ was measured using a turbine ventilometer (Morgan, Model 096, Kent, England). All equipment was calibrated pre and post-test in accordance with national laboratory standards requirements. Every 30s oxygen consumption $\left(\mathrm{VO}_{2}\right)$, ventilation $\left(\mathrm{V}_{\mathrm{E}}\right)$, and ventilatory equivalent for oxygen consumption $\left(\mathrm{V}_{\mathrm{E}} / \mathrm{VO}_{2}\right)$ were calculated and averaged. 


\section{Heart rate}

Prior to the test, participants were fitted with a heart rate monitor (Polar Vantage NV, Polar Electro Oy, Finland). Data was continuously collected and stored for later analysis.

\section{Capillary blood samples}

Prior to commencement and every 10 min during the test, fingertip capillary blood samples were collected for subsequent blood lactate and blood gas analysis $\left(\mathrm{ABL}^{\mathrm{TM}} 700\right.$ Series, Radiometer Medical A/S, Copenhagen, Denmark).

\section{Rating of perceived exertion}

Every $5 \mathrm{~min}$ participants were asked to numerically rate the perceived intensity of exercise (RPE), on a Borg scale of numbers from 6-20.

\section{Endogenous hormones}

Prior to each performance test a resting blood sample was obtained, by routine venepuncture of an antecubital vein. Blood samples were centrifuged, stored in a freezer at $-22^{\circ} \mathrm{C}$ and later analyzed for endogenous serum hormones estradiol and progesterone (PathWest, Laboratory Medicine, WA), using a one-step chemiluminescent competitive immunoassay (\% CV estradiol 4.7, progesterone 5.6).

\section{Statistics}


Descriptive statistics (mean $\pm \mathrm{SD}$ ) were used to characterize the data. The measured variables were averaged over the $60 \mathrm{~min}$ (50 min for oxygen consumption data) and analyzed using a one-way within-subjects repeated measures ANOVA to determine any difference between the OC phases. For results that obtained or approached statistical significance $(p<0.10)$, planned comparisons were tested between particular phases of the repeated measures design (Statistica Version 5, '97 edition). For all tests, statistical significance was preset at $p<0.05$.

\section{RESULTS}

For the endurance performance test, the mean, SD and range of results for measured variables, during each OC phase are presented in Table 2. There was no significant difference in mean power output, body composition, heart rate, $\mathrm{VO}_{2}$, blood glucose or RER between the OC phases $(p>0.05)$. Mean ventilation and mean $\mathrm{V}_{\mathrm{E}} / \mathrm{VO}_{2}(\mathrm{p}=0.001)$ were significantly higher during the CONS $\left(68.9 \pm 10.4 \mathrm{~L}^{\prime} \mathrm{min}^{-1}\right.$ and $\left.27.0 \pm 3.8\right)$ compared to both the WITH1 $(65.5 \pm$ 9.7 L'min ${ }^{-1}$ and $\left.26.0 \pm 3.0\right)$ and WITH2 $\left(63.3 \pm 8.8 \mathrm{~L} \cdot \mathrm{min}^{-1}\right.$ and $\left.25.0 \pm 3.0\right)$. Mean blood lactate was higher in the CONS $\left(6.2 \pm 2.7 \mathrm{mmol} \cdot \mathrm{L}^{-1}\right)$ compared to WITH1 $\left(5.1^{ \pm} 1.9 \mathrm{mmol}^{-1}\right)$. Similarly mean RPE was also higher in the CONS $(14.8 \pm$ 1.0) compared to WITH1 $(14.5 \pm 1.0)(p<0.05)$. Despite the statistical significance, the RPE variation has little physiological relevance, as ratings are expressed in whole numbers.

Endogenous hormonal analysis determined that there was no difference in endogenous progesterone concentration between OC cycle phase $(p>0.05)$. 
In contrast, endogenous serum estradiol did vary between OC cycle phase ( $p$ $=0.028$ ), with planned comparisons detecting that values were significantly higher in WITH2 $\left(179 \pm 190 \mathrm{pmol} \mathrm{L}^{-1}\right)$ compared to WITH1 $\left(87 \pm 74 \mathrm{pmol}^{-1} \mathrm{~L}^{-1}\right)$ and CONS $\left(71^{ \pm} 36 \mathrm{pmol} \cdot \mathrm{L}^{-1}\right)$.

Insert Table 2

\section{DISCUSSION}

The main purpose of this study was to determine whether endurance performance is affected by the acute hormonal variation seen within a monophasic OC cycle. Although the test selected was not sport specific, it was used because of its proven reliability (ICC 0.97 , CV 2.7\%, SEM $3.4 \mathrm{~W}$ ), whilst providing a valid reflection of endurance performance, as opposed to 'time to exhaustion tests', which may be more valid for the assessment of endurance capacity (4). The results demonstrated that mean power output (W) during the1-h cycling performance test, was not influenced by the phase of the OC cycle (CONS $171.8^{ \pm} 25.5 \mathrm{~W}$, WITH1 $172.6 \pm 24.4$, WITH2 $172.5 \pm$ 24.5), with mean differences within the established CV of the test.

We hypothesized that endurance performance would be optimal during CONS, as a result of a shift in substrate metabolism toward increased fat metabolism and reduction in glycogen depletion and blood lactate accumulation. This shift may have potentially suppressed fatigue and enabled the athlete to sustain a higher power output during the test. In contrast to previous findings $(1,21)$, the results from the current study showed the 
opposite, with mean blood lactate being higher in CONS $\left(6.2 \pm 2.7 \mathrm{mmol} \mathrm{L}^{-1}\right)$ compared to WITH1 $\left(5.1^{ \pm} 1.9 \mathrm{mmol}^{-1}\right)$. No other studies have reported an increased lactate production during the luteal phase of the menstrual cycle or within an OC cycle, although many studies have demonstrated no difference $(3,5,6,22)$. Despite the statistical difference, the physiological significance of 1 $\mathrm{mmol} \mathrm{L}^{-1}$ blood lactate change (between 5 and $6 \mathrm{mmol} \mathrm{L}^{-1}$ ) is likely to be relatively small and may be within the typical error of measurement for this variable. It should also be acknowledged that whilst the measure of endurance performance used here has been deemed reliable (4), the reliability of blood lactate measures throughout the test has not been previously assessed. Given there was no corresponding difference in RER or blood glucose concentrations, within the parameters of the study it is difficult to attribute the variation in the lactate result to shifts in substrate metabolism. In further contrast to the hypothesis, the change in blood lactate had no apparent effect upon fatigue or the athlete's ability to sustain power output throughout the performance test.

Despite no difference in endurance performance, some physiological parameters were not constant during the $\mathrm{OC}$ cycle. Mean $\mathrm{V}_{\mathrm{E}}$ was significantly higher during CONS $\left(68.9 \pm 10.4 \mathrm{~L}^{ \pm} \mathrm{min}^{-1}\right)$ compared to both WITH1 and

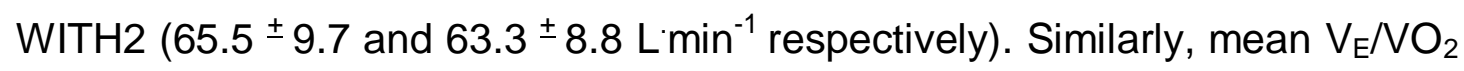
was greater during CONS $\left(27.0^{ \pm} 3.8\right)$ compared to both withdrawal phases $(26.0 \pm 3.0$ and $25.0 \pm 3.0)$. These results support previous findings that implicate progesterone as a factor causing an increase in respiratory drive. The effects of progesterone are thought to be centrally modulated and include 
an increased chemosensitivity to hypoxia and hypercapnia (13). An increased ventilatory response and elevated $\mathrm{V}_{\mathrm{E}} / \mathrm{VO}_{2}$ during the luteal phase of a regular menstrual cycle (when progesterone levels are elevated), has been confirmed during sub maximal aerobic exercise in some studies $(2,24,26)$. Previous OC research has reported no within cycle ventilatory differences $(7,15,20)$. However, the findings of these studies are limited because testing was conducted at two times when the synthetic hormone intake was similar (during OC consumption), as opposed to comparing between OC consumption and withdrawal, when there is a greater contrast in hormone levels. Despite having no impact on the performance outcome, during CONS (when exogenous progesterone levels are high) there was a significant ventilatory inefficiency during the 1-h performance test. It remains unknown whether during a test or event of greater duration and/or intensity, the increased ventilatory cost during the CONS would result in undue respiratory fatigue and diminished performance.

During the study endogenous hormone levels were assessed to quantify a more complete reproductive hormonal profile for each participant. This was based on previous findings (12) that suggest the ratio of estrogen and progesterone (endogenous and/or exogenous) may be relevant in determining the impact of menstrual cycle or OC phase on athletic performance. The OC acts to suppress endogenous hormones, therefore during CONS, production is inhibited. Exogenous estrogen (ethinyloestradiol) is detectable for up to two days after discontinuation of the OC, whilst some exogenous progestins are detectable for up to 5 days (14). Hence, during WITH1 both estrogen and 
progesterone continue to be suppressed, but in WITH2 endogenous progesterone remained suppressed whilst endogenous estrogen increased significantly. The large standard deviation in endogenous estrogen during the withdrawal phases reflects the variation in individual response to $\mathrm{OC}$ treatment. The significant increase in endogenous estrogen from WITH1 (87.3 $\left.\pm 73.6 \mathrm{pmol} \cdot \mathrm{L}^{-1}\right)$ to $\mathrm{WITH} 2\left(178.6 \pm 189.9 \mathrm{pmol} \cdot \mathrm{L}^{-1}\right)$ may support the assessment of the withdrawal phase during two distinct phases.

Overall, there was no change in endurance performance (1-h cycle) throughout an OC cycle in endurance trained female athletes. Therefore, female athletes taking a monophasic OC do not need to be concerned about the timing of their cycle with regards to optimised endurance performance and competition. Despite this finding, the cyclical variation in $\mathrm{V}_{\mathrm{E}}, \mathrm{V}_{\mathrm{E}} / \mathrm{VO}_{2}$ and blood lactate should be considered when interpreting physiological test results.

\section{REFERENCES}

1. Bemben DA, Boileau RA, Bahr JM, Nelson RA, Misner JE. Effects of oral contraceptives on hormonal and metabolic responses during exercise. Med Sci Sports Exerc 1992; 24: 434-441.

2. Bemben DA, Salm PC, Salm AJ. Ventilatory and blood lactate responses to maximal treadmill exercise during the menstrual cycle. J Sports Med Phys Fitness 1995; 35: 257-262.

3. Bernades RP, Radomski MW. Growth hormone responses to continuous and intermittent exercise in females under oral contraceptive therapy. Eur $\mathrm{J}$ Appl Physiol 1998; 79: 24-29. 
4. Bishop D. Reliability of a 1-h endurance performance test in trained female cyclists. Med Sci Sports Exerc 1997; 29: 554-559.

5. Bonen A, Haynes FW, Graham TE. Substrate and hormonal responses to exercise in women using oral contraceptives. J Appl Physiol 1991; 70: 19171927.

6. Bonen A, Haynes FW, Watson-Wright W, Sopper MM, Pierce GN, Low MP, Graham TE. Effects of menstrual cycle on metabolic responses to exercise. J Appl Physiol 1983; 55: 1506-1513.

7. Bryner RW, Toffle RC, Ullrich IH, Yeater RA. Effect of low dose oral contraceptives on exercise performance. Br J Sports Med 1996; 30: 36-40.

8. Brynhildsen J, Lennartsson $\mathrm{H}$, Klemetz M, Dahlquist $\mathrm{P}$, Hedin B, Hammar M. Oral contraceptive use among female elite athletes and age-matched controls and its relation to low back pain. Acta Obstet Gynecol Scand 1997; 76: $873-878$.

9. Casazza GA, Jacobs KA, Suh S-H, Miller BF, Horning MA, Brooks GA. Menstrual cycle phase and oral contraceptive effects on triglyceride mobilization during exercise. J Appl Physiol 2004; 97: 302-309.

10. Casazza GA, Suh S-H, Miller BF, Navazio FM, Brooks GA. Effects of oral contraceptives on peak exercise capacity. J Appl Physiol 2002; 93: 16981702.

11. Daggett A, Davies B, Boobis L. Physiological and biochemical responses to exercise following oral contraceptive use (Abstract). Med Sci Sports Exerc 1983; 15: 174.

12. D'Eon TMD, Sharoff C, Chipkin SR, Grow D, Ruby BC, Braun B. Regulation of exercise carbohydrate metabolism by estrogen and 
progesterone in women. American journal of physiology Endocrinology, metabolism and gastrointestinal physiology 2002; 283: E1046-E1055.

13. England SE, Fahri LE. Fluctuations in alveolar $\mathrm{CO} 2$ and in base excess during the menstrual cycle. Respirat Physiol 1976; 26: 157-161.

14. Fotherby K. Bioavailability of orally administered sex steroids used in oral contraception and hormone replacement therapy. Contraception 1996; 54: 5969.

15. Grucza R, Pekkarinen H, Hanninen O. Cardiorespiratory responses to bicycle incremental exercise in women taking oral contraceptives. Biol Sport 2002; 19: 267-279.

16. Jacobs KA, Casazza GA, Suh S-H, Horning MA, Brooks GA. Fatty acid reesterification but not oxidation is increased by oral contraceptive use in women. J Appl Physiol 2005: 1720-1731.

17. Janse de Jonge XAK. Effects of the menstrual cycle on exercise performance. J Sports Med 2003; 33(11): 833-851.

18. Lebrun CM. Effect of the different phases of the menstrual cycle and oral contraceptives on athletic performance. Sports Med 1993; 16: 400-430.

19. Lebrun CM, Petit MA, McKenzie DC, Taunton JE, Prior JC. Decreased maximal aerobic capacity with use of a triphasic oral contraceptive in highly active women: a randomised controlled trial. Br J Sports Med 2003; 37: 315320.

20. Lynch NJ, De Vito G, Nimmo MA. Low dosage monophasic oral contraceptive use and intermittent exercise performance and metabolism in humans. Eur J Appl Physiol 2001; 84: 296-301. 
21. McNeill AW, Mozingo E. Changes in the metabolic cost of standardized work associated with the use of an oral contraceptive. J Sports Med 1981; 21 : 238-244.

22. Nicklas BJ, Hackney AC, Sharp RL. The menstrual cycle and exercise: Performance, muscle glycogen and substrate responses. Int J Sports Med 1989; 10: 264-269.

23. Redman LM, Hamdorf P, Norman RJ, Westlander G, Scroop GC. The Menstrual cycle or oral contraceptive pill: Can it benefit or hinder exercise in women? Med Sci Sports Exerc 2004; 36(5): S280.

24. Schoene RB, Robertson HT, Pierson DJ, Peterson AP. Respiratory drives and exercise in menstrual cycles of athletic and nonathletic women. J Appl Physiol: Respirat Environ Exercise Physiol 1981; 50: 1300-1305.

25. Suh S-H, Casazza GA, Horning MA, Miller BF, Brooks GA. Effects of oral contraceptives on glucose flux and substrate oxidation rates during rest and exercise. J Appl Physiol 2003; 94: 285-294.

26. Williams TJ, Krahenbuhl GS. Menstrual cycle phase and running economy. Med Sci Sports Exerc 1997; 29: 1609-1618. 
Table 1: Individual characteristics of participants $(n=13)$.

\begin{tabular}{|c|c|c|c|c|c|c|}
\hline \multirow{2}{*}{$\begin{array}{c}\text { Participant } \\
\text { No. }\end{array}$} & \multirow{2}{*}{$\begin{array}{l}\text { Age } \\
(y)\end{array}$} & \multicolumn{2}{|c|}{ Oral Contraceptive Formulation } & \multirow{2}{*}{$\begin{array}{c}\text { Time } \\
\text { Taking OC } \\
\text { (months) }\end{array}$} & \multirow{2}{*}{$\begin{array}{c}\text { Cycling } \\
\text { Experience } \\
\text { (y) }\end{array}$} & \multirow{2}{*}{$\begin{array}{c}\text { Average } \\
\text { Training } \\
\text { (km/week) } \\
\end{array}$} \\
\hline & & Ethinyloestradiol & Progestin & & & \\
\hline 1 & 19 & 30 mcg ethinyloestradiol & 150 mcg levonorgestrel & 18 & 2.0 & 150 \\
\hline 2 & 32 & 35 mcg ethinyloestradiol & 2000 mcg cyproterone acetate & 60 & 5.0 & 200 \\
\hline 3 & 30 & 35 mcg ethinyloestradiol & $1 \mathrm{mg}$ norethisterone & 36 & 3.0 & 200 \\
\hline 4 & 28 & 20 mcg ethinyloestradiol & 100 mcg levonorgestrel & 6 & 5.0 & 250 \\
\hline 5 & 31 & 35 mcg ethinyloestradiol & 500 mcg norethisterone & 96 & 5.5 & 200 \\
\hline 6 & 35 & 30 mcg ethinyloestradiol & 150 mcg desogestrel & 24 & 3.0 & 200 \\
\hline 7 & 43 & 30 mcg ethinyloestradiol & 150 mcg levonorgestrel & 96 & 1.5 & 150 \\
\hline 8 & 39 & 35 mcg ethinyloestradiol & $500 \mathrm{mcg}$ norethisterone & 60 & 3.0 & 200 \\
\hline 9 & 31 & 30 mcg ethinyloestradiol & 150 mcg levonorgestrel & 120 & 2.0 & 150 \\
\hline 10 & 27 & 30 mcg ethinyloestradiol & 3 mg drospirenone & 6 & 4.0 & 250 \\
\hline 11 & 43 & 30 mcg ethinyloestradiol & 150 mcg levonorgestrel & 36 & 0.5 & 100 \\
\hline 12 & 43 & 20 mcg ethinyloestradiol & 100 mcg levonorgestrel & 60 & 1.5 & 170 \\
\hline 13 & 36 & 30 mcg ethinyloestradiol & 150 mcg desogestrel & 84 & 2.5 & 400 \\
\hline Mean & 34 & & & 54 & 3.0 & 202 \\
\hline SD & 7 & & & 37 & 1.5 & 73 \\
\hline
\end{tabular}


Table 2: Mean ${ }^{ \pm}$standard deviation and range of dependent variables during the performance tests, at different times of the OC cycle.

\begin{tabular}{|c|c|c|c|}
\hline VARIABLE & WITH1 & WITH2 & CONS \\
\hline Mean body mass $(\mathrm{kg})$ & $61.6 \pm 15.3$ & $61.5 \pm 15.3$ & $61.6 \pm 15.2$ \\
\hline \multirow{2}{*}{ Mean sum of skinfolds (mm) } & $(54.2-76.0)$ & $(53.1-76.0)$ & $(54.1-76.3)$ \\
\hline & $78.5 \pm 26.2$ & $80.4 \pm 28.7$ & $80.2 \pm 29.0$ \\
\hline \multirow{2}{*}{ Mean serum oestradiol $\left(\mathrm{pmol} \cdot \mathrm{L}^{-1}\right)$} & $(37.1-109.7)$ & $(37.1-116.5)$ & $(37.3-109.7)$ \\
\hline & $87 \pm 74$ & $179^{ \pm} 190^{a, b}$ & $71^{ \pm} 36$ \\
\hline \multirow{3}{*}{$\begin{array}{l}\text { Mean serum progesterone } \\
\left(\mathrm{nmol} \mathrm{L}^{-1}\right)\end{array}$} & $(40-270)$ & $(40-680)$ & $(40-130)$ \\
\hline & $3.2^{ \pm} 0.4$ & $3.1^{ \pm} 0.3$ & $3.2^{ \pm} 0.4$ \\
\hline & $(3.0-4.0)$ & $(3.0-4.0)$ & $(3.0-4.0)$ \\
\hline Mean power output (W) & $\begin{array}{c}172.6 \pm 24.4 \\
(158-232)\end{array}$ & $\begin{array}{c}172.5 \pm 24.5 \\
(155-237)\end{array}$ & $\begin{array}{c}171.8 \pm 25.5 \\
(156-239)\end{array}$ \\
\hline \multirow[t]{2}{*}{ Mean heart rate (bpm) } & $163 \pm 11$ & $164 \pm 11$ & $166 \pm 11$ \\
\hline & $(142-184)$ & $(138-182)$ & $(139-178)$ \\
\hline \multirow[t]{2}{*}{$\%$ peak heart rate } & $87 \pm 4$ & $88 \pm 3$ & $89 \pm 2$ \\
\hline & $(79-94)$ & $(80-93)$ & $(85-93)$ \\
\hline \multirow[t]{2}{*}{ Mean RPE } & $14.5^{ \pm} 1.0^{\mathrm{a}}$ & $14.5 \pm 1.0$ & $14.8 \pm 1.0$ \\
\hline & $(12.4-15.8)$ & $(12.7-15.5)$ & $(12.9-16.3)$ \\
\hline \multirow[t]{2}{*}{ Mean $V_{E}\left(L \cdot \min ^{-1}\right)$} & $65.5^{ \pm} 9.7^{\mathrm{a}}$ & $63.3^{ \pm} 8.8^{\mathrm{a}}$ & $68.9 \pm 10.4$ \\
\hline & $(51.3-85.3)$ & $(52.2-81.8)$ & $(55.9-87.3)$ \\
\hline \multirow[t]{2}{*}{ Mean $\mathrm{VO}_{2}\left(\mathrm{~mL} \mathrm{~kg}^{-1} \cdot \mathrm{min}^{-1}\right)$} & $41.3^{ \pm} 5.5$ & $41.4 \pm 5.3$ & $41.7 \pm 5.6$ \\
\hline & $(33.6-47.9)$ & $(35.9-47.1)$ & $(34.9-48.9)$ \\
\hline \multirow[t]{2}{*}{$\%$ peak $\mathrm{VO}_{2}$} & $77.8 \pm 4.7$ & $77.9 \pm 4.1$ & $78.5 \pm 4.5$ \\
\hline & $(70.7-84.9)$ & $(72.9-82.7)$ & $(73.4-84.8)$ \\
\hline \multirow[t]{2}{*}{ Mean $\mathrm{V}_{\mathrm{E}} / \mathrm{VO}_{2}$} & $26.0^{ \pm} 3.0^{\mathrm{a}}$ & $25.0^{ \pm} 3.0^{\mathrm{a}}$ & $27.0^{ \pm} 3.8$ \\
\hline & $(22.6-30.5)$ & $(21.5-29.4)$ & $(22.8-32.9)$ \\
\hline \multirow[t]{2}{*}{ Mean blood lactate $\left(\mathrm{mmol} \cdot \mathrm{L}^{-1}\right)$} & $5.1^{ \pm} 1.9^{a}$ & $5.6 \pm 2.2$ & $6.2 \pm 2.7$ \\
\hline & $(2.7-8.7)$ & $(2.3-9.3)$ & $(2.3-9.8)$ \\
\hline \multirow[t]{2}{*}{ Mean blood glucose $\left(\mathrm{mmol}^{-1} \mathrm{~L}^{-1}\right)$} & $5.5 \pm 0.8$ & $5.5 \pm 0.9$ & $5.3 \pm 2.0$ \\
\hline & $(4.6-7.2)$ & $(3.9-6.9)$ & $(4.0-7.4)$ \\
\hline \multirow[t]{2}{*}{ Mean RER } & $0.93 \pm 0.02$ & $0.94 \pm 0.02$ & $0.94 \pm 0.02$ \\
\hline & $(0.90-0.96)$ & $(0.88-0.97)$ & $(0.90-0.97)$ \\
\hline
\end{tabular}

a significantly different to CONS $(p<0.05)$

${ }^{b}$ significantly different to WITH1 $(p<0.05)$

CONS - between days 13 and 17 of active OC consumption 
WITH1 - early in the OC withdrawal phase, 2-3 days post active pill cessation WITH2 - late in the OC withdrawal phase, 6-7 days post active pill cessation

RPE - rating of perceived exertion

$V_{E}-$ minute rate of ventilation

$\mathrm{VO}_{2}-$ minute rate of oxygen consumption

$V_{E} / \mathrm{NO}_{2}$ - ventilatory equivalent for oxygen consumption

RER - respiratory exchange ratio 